\title{
Using Sawdust to Treat Synthetic Municipal Wastewater and Its Consequent Transformation Into Biogas
}

\author{
Zaidun Naji Abudi ${ }^{1}$ \\ 1 Environmental Engineering Department, Faculty of Engineering, Al-Mustansiryiah University, Baghdad, Iraq, \\ e-mail:Zaidun.naji77@uomustansiriyah.edu.iq
}

\begin{abstract}
Sawdust, as an agricultural waste which is highly efficient, readily available, and relatively inexpensive, has the potential to be an applicable alternative adsorbent for the total organic carbon (TOC) removal from synthetic domestic wastewater. This study aims firstly to investigate the feasibility of sawdust as a new adsorbent and understand its adsorption mechanism for TOC. The impact of particle size, $\mathrm{pH}$, contact time, and temperature has been evaluated as the controlling factors on the adsorption process. The results presented that the removal efficiency rose with the decrease of particle size, $\mathrm{pH}$, and temperature, as well as the increase of the contact time. The maximum adsorption was obtained at particle size of $0.05 \mathrm{~mm}, \mathrm{pH}$ of 1 , contact time of $1.5 \mathrm{~h}$, and temperature of $15^{\circ} \mathrm{C}$, respectively. The second aim of this study is to utilize the sawdust that is used in the adsorption process as biomass in batch anaerobic digestion (AD) to produce methane. Spent sawdust was characterized by the methane production which was 5.9 times greater than in the case of raw sawdust. Four operating parameters were checked, Carbon/Nitrogen ratio $(\mathrm{C} / \mathrm{N})$, inoculation, particle size, and total solid (TS) content. The batch results indicated that the optimum parameters were: $20 \%, 30 \%, 2 \mathrm{~mm}$, and $15 \%$, respectively.
\end{abstract}

Keywords: Anaerobic digestion; sawdust; adsorption; total organic carbon

\section{INTRODUCTION}

The three main problems faced by the world today are water, food, and energy supply. In order to solve these problems, the domestic wastewater is now treated as a resource rather than as a waste (Benetti, 2008). The 1st and 3rd problems can be addressed through the use of treated wastewater for domestic consumption, including landscape and crop irrigation, which is widely accepted and used to save water as well as utilize the fertilizing elements it contains. The domestic wastewater can be used as a source for energy through anaerobic digestion, to solve the $3 \mathrm{rd}$ problem, which involves the methane gas $\left(\mathrm{CH}_{4}\right)$ production from wastewater organic content by anaerobic conversion (Speece, 2007). The organic fraction in wastewater is the most direct and commonly exploited energy source. This fraction is a diverse mixture of molecules with a varied structure and molecular weight. It contains $\sim 42 \%$ dissolved organic carbon, $\sim 27 \%$ settleable organic carbon, $\sim 20 \%$ supracolloidal organic carbon, and $\sim 11 \%$ colloidal organic carbon (Rickert \& Hunter, 1971). If these compounds are not removed properly from wastewater through the wastewater treatment plants (WWTPs), and are discharged into water resources (rivers or lakes), they may constitute an environmental problem. This problem has a harmful effect on the water quality and also affects the aquatic life (Huerta-Fontela et al., 2011).

WWTPs remove or minimize the nutrients such as carbon, nitrogen, and phosphorus. Most of the existing treatment processes involve advanced methods (likes activated carbon, photooxidation, ozonation, and UV radiation) because the biological treatment alone is not sufficient (Ahn \& Logan, 2010; Katsoyiannis \& Samara, 2005). Nevertheless, these advanced methods using ozonaiton and UV light are expensive since they require greater technical experience and are characterized by high energy consumption. Addi- 
tionally, when activated carbon is used, the steps of its activation and regeneration are delicate and too costly; moreover, additional tertiary filtration is frequently required (Shukla et al., 2010; Yin et al., 2007). In order to treat wastewater by removing nutrients such as TOC efficiently, new waste materials, especially agricultural wastes like sawdust, wood chips etc., have the economic advantages of obtaining low-cost feedstocks for wastewater treatment and minimizing waste disposal costs. In addition, it offers environmental advantages like reusing and reducing wastes and energy recovery (Yang et al., 2017).

Although sawdust, like any biomass, can be explored as a biogas source, it is far less used as a feedstock for biogas production (Castoldi et al., 2017). Therefore, in this study, it is used for the removal of TOC from wastewater and then for biogas $\left(\mathrm{CH}_{4}\right)$ production by anaerobic digestion process. Anaerobic digestion (AD) is the process of converting biomass into biogas energy. This process was used for the production of renewable energy so as to achieve stable energy alternatives that will meet the world demand while mitigating the climate change through reduction of emissions. AD constitutes an economical, eco-friendly, renewable energy source which can produce bio-fertilizers as a by-product (Kimming et al., 2011; Lizasoain et al., 2016).

The main objectives of the present study were to (i) investigate the effects of the adsorption process parameters (particle size, dose, temperature, reaction time, and wastewater $\mathrm{pH}$ ) on the TOC removal by sawdust and (ii) evaluate its potential biogas production by $\mathrm{AD}$ of sawdust after the adsorption process; the influence of different operation factors (particle size, inoculum percent, $\mathrm{C} / \mathrm{N}$ ratio, and T.S content) was checked as well.

\section{MATERIALS AND METHODS}

\section{Raw materials}

Our main material (pine sawdust) was brought from a furniture factory of Huazhong University of Science and Technology (HUST), Wuhan, China. The pine sawdust was naturally dried for eight days, then crushed and sieved to four different particle sizes. The ultimate and proximate analyses of sawdust are given in Table 1 (wt $\%$, air-dried basis). Synthetic wastewater in this study was prepared to simulate the characteristics of Chinese municipal wastewater. Its composition was as follows (mg/L): Glucose (332), $\mathrm{NH}_{4} \mathrm{CL}$ (210), $\mathrm{KH}_{2} \mathrm{PO}_{4}$ (21.95), $\mathrm{MgSO}_{4}(50), \mathrm{ZnCl}_{2}(50)$, and a $1 \mathrm{ml}$ trace element mixture, consisting of 0.075 $\mathrm{g} \mathrm{CaCl}_{2}, 0.04 \mathrm{~g} \mathrm{CuCl}_{2} \mathrm{H}_{2} \mathrm{O}, 0.048 \mathrm{~g} \mathrm{NiCl}_{2} .6 \mathrm{H} 2 \mathrm{O}$, $0.044 \mathrm{~g} \mathrm{FeSO}_{4} .7 \mathrm{H}_{2} \mathrm{O}$ and $0.120 \mathrm{~g} \mathrm{H}_{3} \mathrm{BO}_{3}$. In order to keep the $\mathrm{pH}$ of the synthetic wastewater at 6.8-7.2, $100 \mathrm{mg} / \mathrm{L} \mathrm{NaHCO}_{3}$ was added. The inoculum used for anaerobic digestion process with a total solid content (TS\%, 4.25), volatile solid content (VS\%, 69.0) and $\mathrm{pH}(7.2)$ was collected from the active mesophilic anaerobic reactor in the same lab that treated pig manure to produce biogas. All chemicals and reagents used in this study were of analytical grade.

\section{Batch adsorption process}

In order to study removal of TOC from synthetic domestic wastewater by pine sawdust, adsorption experiments in batch mode were carried out. The effects of different factors, including particle size (0.05-1 mm), pH (1-9), adsorbent dose $(0.1-0.9 \mathrm{~g} / 50 \mathrm{ml})$, contact time $(10 \mathrm{~min}-4 \mathrm{~h})$, and temperature $\left(15-50{ }^{\circ} \mathrm{C}\right)$ were investigated. The $\mathrm{pH}$ of the solution was adjusted with $0.1 \mathrm{M}$ $\mathrm{HCl}$ and $0.1 \mathrm{M} \mathrm{NaOH}$. The weighted absorbents were added to $50 \mathrm{~mL}$ of wastewater in a $150 \mathrm{~mL}$ Erlenmeyer flask and then mixed at $200 \mathrm{rpm}$ for the desired contact time at a specific temperature in a water bath shaker. At the end of adsorption process, and after centrifuging solutions, the suspensions were separated; afterwards, the TOC concentrations were measured according to a standard method (APHA). The adsorption capacity and percentage removal of TOC by sawdust were determined by Eqs. (1) and (2), respectively:

$$
q_{e}=\frac{C_{o}-C_{e}}{m}
$$

$$
\text { \%removal TOC }=\frac{C_{o}-C_{e}}{C_{o}} \times 100
$$

where $q_{e}(\mathrm{mg} / \mathrm{g})$ represents the adsorption capacity.

$C_{o}(\mathrm{mg} / \mathrm{L})$ and $\mathrm{C}_{\mathrm{e}}(\mathrm{mg} / \mathrm{L})$ is the initial and final concentration of TOC, respectively. $V(\mathrm{ml})$ is the volume of TOC solution, $m(g)$ is the weight of the dried adsorbents.

\section{Anaerobic digestion process}

The anaerobic digestion experiments were conducted in a batch mode using $1 \mathrm{~L}$ Duran glass bottles with a working volume of $0.6 \mathrm{~L}$. Two 
Table 1. Characteristics of pine sawdust

\begin{tabular}{|c|c|c|c|c|c|c|c|c|}
\hline \multicolumn{5}{|c|}{ Ultimate analysis $^{\mathrm{a}}$} & \multicolumn{4}{c|}{ Proximate analysis $^{\mathrm{b}}$} \\
\hline Carbon & Hydrogen & Nitrogen & Oxygen $^{\mathrm{c}}$ & Sulfur & Moisture & Volatile & Ash & Fixed carbon $^{-1}$ \\
\hline 47.15 & 6.22 & 0.18 & 45.20 & 0.16 & 6.95 & 78.01 & 1.09 & 13.95 \\
\hline
\end{tabular}

groups of batches were conducted based on the objectives of this study; the first one was fed with raw sawdust and the other was fed with sawdust used in the adsorption process. At the same time, the bottles only fed with the inoculum were used as a control. All the experiments were conducted in duplicate. Four different parameters were studied in these batch tests, i.e. substrates particle size $(0.3,0.8,1.0$, and $2.0 \mathrm{~mm})$, inoculum percent (10, 20 , and $30 \%)$, carbon to nitrogen $(\mathrm{C} / \mathrm{N})$ ratio $(20$, 25 , and $30 \%$ ), and total solid (TS) content $(5,10$, and $15 \%$ ). Each parameter was studied alone and others were kept fixed. After adding the designed amounts of sawdust and inoculum in the batch digesters, the $\mathrm{C} / \mathrm{N}$ ratio and $\mathrm{TS} \%$ were checked. Prior to sealing, each bottle was flushed with nitrogen gas ( $99.9 \%$ purity) for $2-5$ min to confirm anaerobic conditions. Then, the bottles were tightly closed with rubber stopper and caps and placed in a water bath shaker at $\left(35^{\circ} \mathrm{C}\right)$ and stirred at $100 \mathrm{rpm}$. During the batch test, the daily biogas produced in the reactor flowed through a bottle filled with $3 \mathrm{M} \mathrm{NaOH}$ solution for $\mathrm{CO}_{2}$-fixation and remaining methane $\left(\mathrm{CH}_{4}\right)$, which was measured with the water displacement method.

\section{Analytical methods}

The water quality parameters, including total organic carbon (TOC), total Kjeldahl nitrogen (TKN), total solids (TS) and volatile solids (VS) were determined according to Standard Methods (Federation \& Association, 2005). The $\mathrm{pH}$ of the solution was measured using a pHS-25C pH meter made by Shanghai Precision \& Scientific Instrument Co., Ltd. The carbon and nitrogen analysis was conducted using a Vario EL (element analyzer) made by Elementar Analysensysteme $\mathrm{GmbH}$. The $\mathrm{CH}_{4}$ content was analyzed via gas chromatography (SP-2100, China).

\section{RESULTS AND DISCUSSIONS}

\section{Adsorption results}

Adsorptive removal of TOC was studied for four different particle sizes of pine sawdust equalling $\mathrm{r}<0.05, \quad 0.2<\mathrm{r}<0.3, \quad 0.3<\mathrm{r}<0.5$, and $0.5<\mathrm{r}<1 \mathrm{~mm}$. As shown in Figure 1a, the rate of adsorption was influenced by the size distribution. It is interesting to note that an increase in the TOC adsorption percentage occurs from $13.0 \%$ to $46.5 \%$ when the adsorbent size decreases from $0.5<r<1 \mathrm{~mm}$ to $\mathrm{r}<0.05 \mathrm{~mm}$. This behaviour can be explained due to the accessibility to larger surface area of the adsorbent for adsorption (Gupta et al., 2015).

In order to study the effect of adsorbent dose in solution on the TOC adsorption percentage, different dosage was used (ranging from 0.1 to $0.9 \mathrm{~g} / 50 \mathrm{~mL}$ ) and the results are shown in Figure 1b. It was observed that the removal efficiency increases along with the amount of adsorbent in the solution. This can be attributed to the increase in the accessibility of adsorption sites for the TOC. Many studies are in agreement with the current work results (Kazemi et al., 2016; Khamparia \& Jaspal, 2016; Mor et al., 2016) where they reported that the sorption of pollutant increases as dosages increased. On the other hand, a reverse trend was observed with the adsorption capacity which decreased as the adsorbent dosage was increased (Figure $1 \mathrm{~b}$ ). The reason of this was possibly due to the particle interaction, such as aggregation, resulting from high adsorbent dosage, which lead to a decrease in the total surface area of the adsorbent and increase in the diffusional path length (Ghaedi et al., 2012).

The $\mathrm{pH}$ value of the initial wastewater is the most important parameter affecting the adsorption of TOC. The uptake of TOC by pine sawdust was studied as a function of $\mathrm{pH}$ ranging from 1 to 9 . The results show that the removal percentage of TOC from the synthetic wastewater decreased with the rise in $\mathrm{pH}$ of the solution (Figure1c). Maximum 62\% TOC adsorption was obtained at $\mathrm{pH} 1$ indicating that the TOC removal is more efficient under acidic conditions and it minimizes to $12 \%$ with a rise in $\mathrm{pH}$ to 9 . These results were consistent with the previous studies, where it also showed that the adsorption percentage increased with $\mathrm{pH}$ reduction (Khamparia \& Jaspal, 2016; Liu et al., 2016; Mor et al., 2016).

The extent of TOC taken up from synthetic municipal wastewater by pine sawdust was addi- 
tionally verified as a function of contact time. The contact time was changed from $10 \mathrm{~min}$ to $4 \mathrm{~h}$. The results of the contact time effects are shown in Figure 1d. It is clear from Figure 1d that equilibrium was reached after $1.5 \mathrm{~h}$ of contact time (removal percent was 36\%). Afterwards, as shown in Figure 1d, the TOC removal was decreased to $32 \%$. On the basis of the findings from contact time experiments, $1.5 \mathrm{~h}$ was taken as equilibrium time in next adsorption studies.

The impact of temperature on the TOC adsorption by pine sawdust was checked (Figure1e). Five temperatures were used in this part of adsorp- tion experiment $\left(15-50^{\circ} \mathrm{C}\right)$. As can be seen, the TOC removal percent decreases sharply with the rising temperature from $15^{\circ} \mathrm{C}$ to $50^{\circ} \mathrm{C}$. Maximum TOC removal of $37 \%$ was observed at $15^{\circ} \mathrm{C}$ and decreased to $17 \%$ at $50^{\circ} \mathrm{C}$. Many studies reported increases in the adsorption percentage along with temperature (El-Naas et al., 2010; Kazemi et al., 2016). This indicates the exothermic nature of the adsorption process. Moreover, the decrease of adsorption with increasing temperature can be explained by the weakening of the sorptive forces between the active sites on the sorbent and the adsorptive species (Mor et al., 2016).
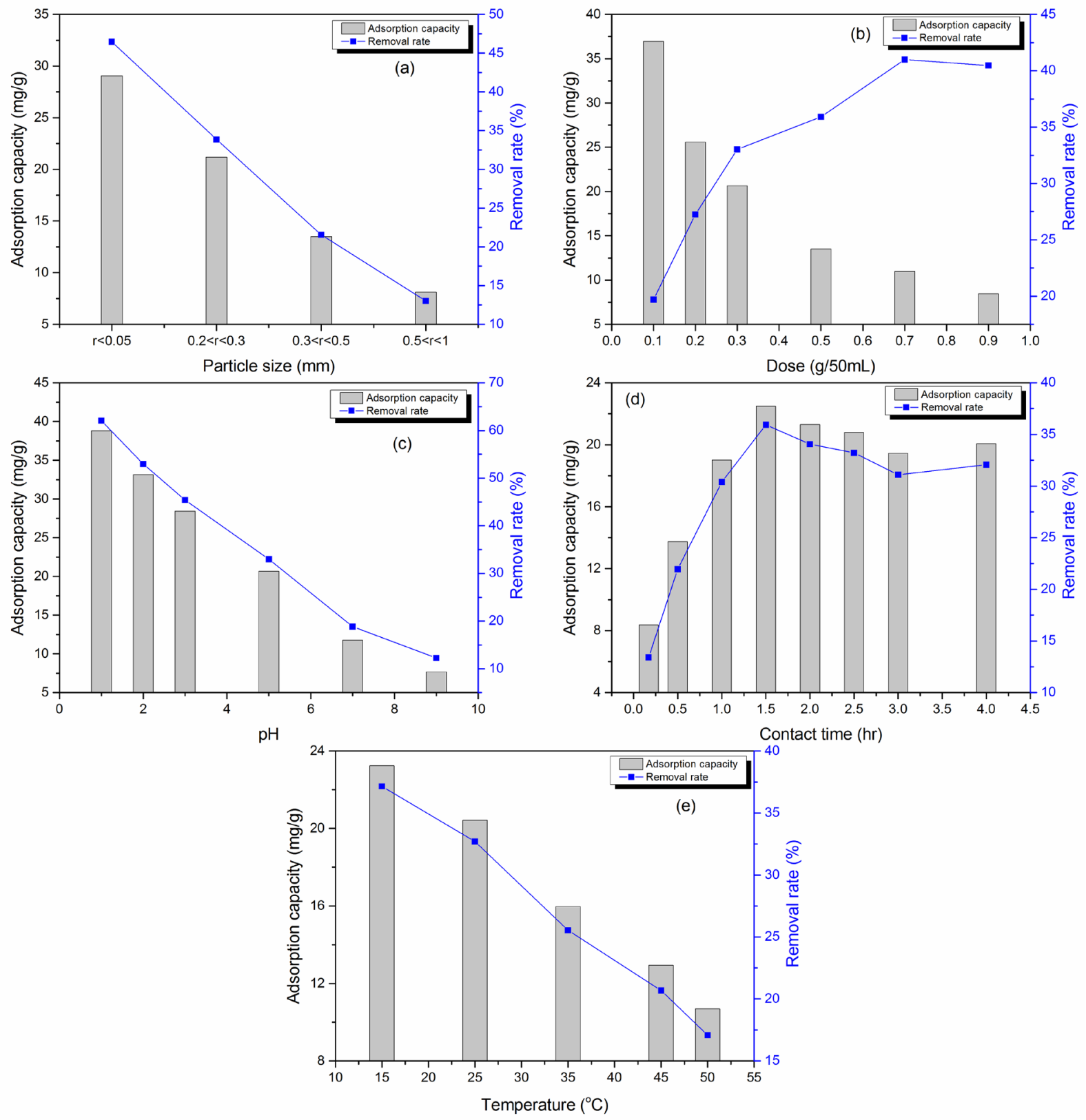

Figure 1. Effect of (a) particle size, (b) adsorbent dosage, (c) pH, (d) contact time, and (e) temperature on adsorption process 


\section{Anaerobic digestion results}

The second part of this paper was to study the anaerobic digestion of sawdust after using it in the adsorption process. This part was divided into five groups: the first one checked the effect of TOC adsorbed on sawdust on AD of sawdust, while the other four groups investigated the effects of $\mathrm{C} / \mathrm{N}$ ratio, inoculum percentage, particle size, and TS content on the AD process and biogas production.

In order to study the feasibility of anaerobic digestion of sawdust before and after the adsorption process, batch tests were conducted on both sawdust (raw and spent) and the results were illustrated in Figure 2. It is clear from Figure 2 that the AD of spent sawdust was a very important step of adsorption process because of the great amount of energy that can be recovered from it instead of being wasted. Figure 2 shows that the digestion process of raw sawdust did not take more than 25 days and stopped, while for spent sawdust, the process continued for 45 days. Maximum daily $\mathrm{CH}_{4}$ produced by spent sawdust was $1250 \mathrm{~mL} / \mathrm{d}$, which was $290 \%$ more than maximum $\mathrm{CH}_{4}$ produced from raw sawdust (Figure 2a), this may be due to the large amount of TOC adsorbed on sawdust, which can be digested easily by microorganisms. Figure $2 \mathrm{~b}$ showed the cumulative $\mathrm{CH}_{4}$ produced from digestion process. It can be seen that the reused sawdust had a significantly higher $\mathrm{CH}_{4}$ production (5.9 times) compared to raw sawdust. Therefore, using low-cost biomass has a great theoretical and practical value for treatment of municipal sewage, removal of the hydrocarbon resources from sewage, and finally using absorbent as raw materials to produce biogas energy.
Three different $\mathrm{C} / \mathrm{N}$ ratios $(20 \%, 25 \%$, and $30 \%$ ) were carried out to find the optimum ratio. The results were shown in Figure 3. As can be seen in Figure 3, the best $\mathrm{C} / \mathrm{N}$ ratio was $20 \%$ for $\mathrm{CH}_{4}$ production volume. The batch reactor with $\mathrm{C} / \mathrm{N}$ of $20 \%$ had the maximum daily $\mathrm{CH}_{4}$ production $(1075 \mathrm{~mL} / \mathrm{d})$, which was $28 \%$ and $55 \%$ more than the production of reactors with $\mathrm{C} / \mathrm{N}$ of $25 \%$ and 30\%, respectively (Figure 3a). Additionally, cumulative $\mathrm{CH}_{4}$ produced from a batch with $\mathrm{C} / \mathrm{N}$ ratio of $20 \%(8775 \mathrm{~mL})$ was higher than other batches by $14 \%$ and $23 \%$, respectively (Figure $3 \mathrm{~b})$. The result of this parameter was consistent with the previous studies, where the optimum $\mathrm{C} / \mathrm{N}$ ratio was $20-30 \%$. In a study conducted by Yen and Brune to investigate the effect of $\mathrm{C} / \mathrm{N}$ ratio on the anaerobic co-digestion of algal sludge and waste paper, the results showed that the optimized $\mathrm{C} / \mathrm{N}$ ratio for the co-digestion was $20 / 1$ to 25/1 (Yen \& Brune, 2007). Haider et al. (2015) carried out another study to investigate the anaerobic co-digestion of food waste and rice husk. Their results showed that highest specific biogas yield of $584 \mathrm{~L} / \mathrm{kg}$ VS was obtained from feedstock with $\mathrm{C} / \mathrm{N}$ ratio of 20 (Haider et al., 2015).

In order to study the effect of inoculum amount on the anaerobic digestion of sawdust, batch experiments with three inoculum amounts $(10,20$, and $30 \%$ ) were conducted. The experiments were continued for 40 days. Figure 4 shows the daily and cumulative $\mathrm{CH}_{4}$ production of sawdust digestion. As can be seen, the $\mathrm{CH}_{4}$ production increased along with the inoculum percentage. This can be explained by the fact that when the inoculum amount decreases, it may cause overload, the unfavourable situation where there was too much biomass for the microorganisms to digest.
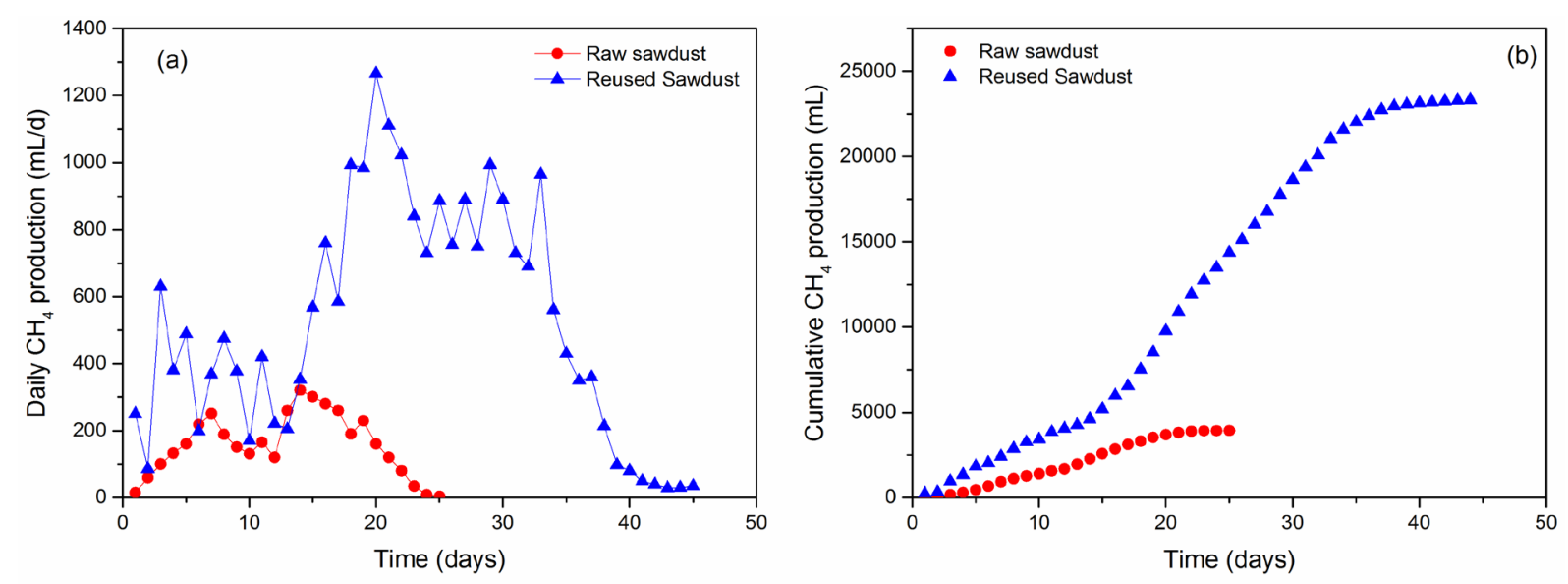

Figure 2. Effect of TOC on AD of sawdust 

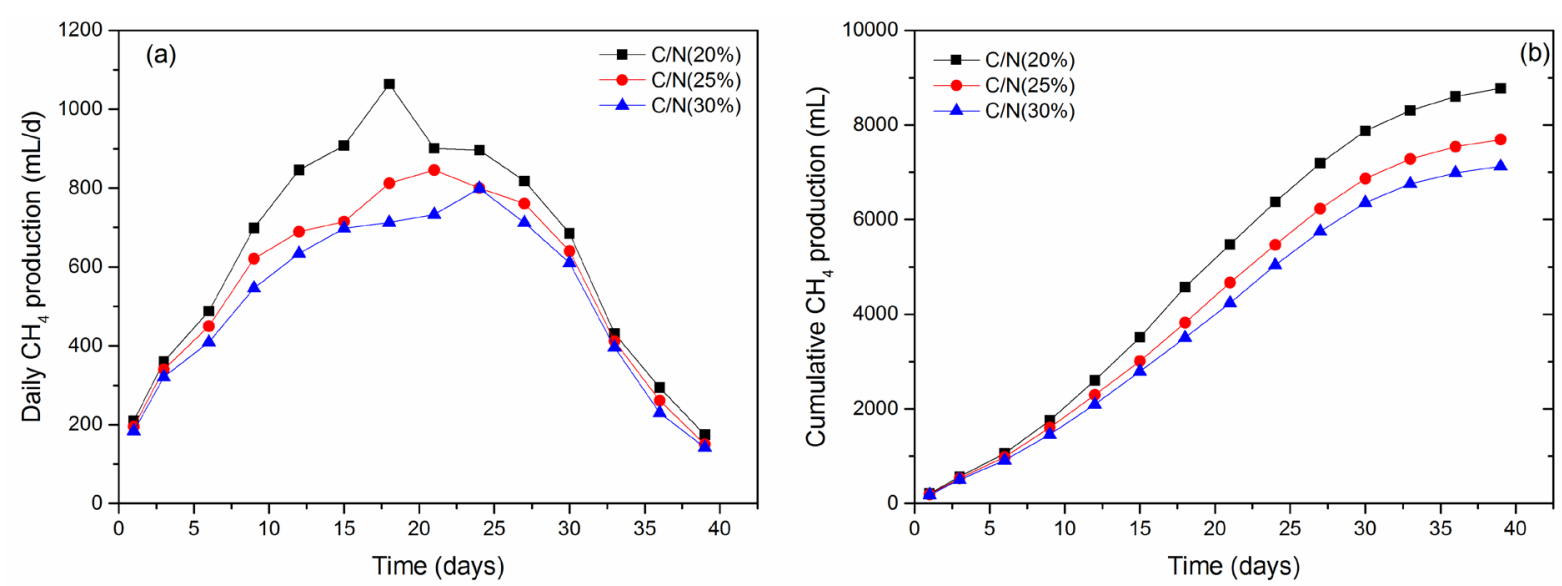

Figure 3. Effect of $\mathrm{C} / \mathrm{N}$ ratio on $\mathrm{AD}$ of sawdust

Thus, higher inoculum could supply some kind of safety factor in the BMP assay since the appropriate inoculum is able to process a higher flow of metabolites (Dechrugsa et al., 2013). Maximum daily $\mathrm{CH}_{4}$ produced was $1370 \mathrm{~mL} / \mathrm{d}$ achieved by $30 \%$ inoculum amount, which was $52 \%$ and $26 \%$ more than other inoculum percentages, respectively (Figure 4a). The cumulative $\mathrm{CH}_{4}$ production after 40 days of $\mathrm{AD}$ of sawdust with $10 \%$, $20 \%$, and $30 \%$ inoculum percent were 7940 , 8275 , and $8700 \mathrm{~mL}$, respectively (Figure 4b). This result was comparable to previous studies, where the biogas production increased along with the inoculum amount (Dechrugsa et al., 2013; Haider et al., 2015).

One of the parameters investigated in this study was biomass particle size and its effect on $\mathrm{AD}$ of sawdust and biogas produced. As can be seen from Figure 5, the best particle size was $2 \mathrm{~mm}$. Maximum daily $\mathrm{CH}_{4}$ production $(1700 \mathrm{~mL} / \mathrm{d})$ was achieved by $2 \mathrm{~mm}$ particle size with no significant difference with a $1 \mathrm{~mm}$ par- ticle size $(1590 \mathrm{~mL} / \mathrm{d})$, but it has a significant difference with other sizes 0.3 and $0.8 \mathrm{~mm}, 107 \%$ and $31 \%$, respectively (Figure 5a). Additionally, the cumulative $\mathrm{CH}_{4}$ produced during the entire digestion time, the batch with $2 \mathrm{~mm}$ particle size had the highest amount of $\mathrm{CH}_{4}$ generated. This particle size showed a 2.3- and 1.5-fold higher $\mathrm{CH}_{4}$ volume than 0.3 and $0.8 \mathrm{~mm}$ particle sizes, respectively. A small difference $(2.5 \%)$ was achieved with $1 \mathrm{~mm}$ particle sizes. These results were in agreement with previous studies (Agyeman \& Tao, 2014; De la Rubia et al., 2011; Zhang \& Banks, 2013). Zhang and Banks conducted a study to check the impact of different particle sizes on AD of the organic fraction of municipal solid waste. Their results indicated that the digester with the $2 \mathrm{~mm}$ mean particle size was characterized by slightly higher methane production than the $4 \mathrm{~mm}$ mean particle size (Zhang \& Banks, 2013). In another study, Agyeman and Tao found in their work that the maximum methane production rate and specific methane yield were signifi-
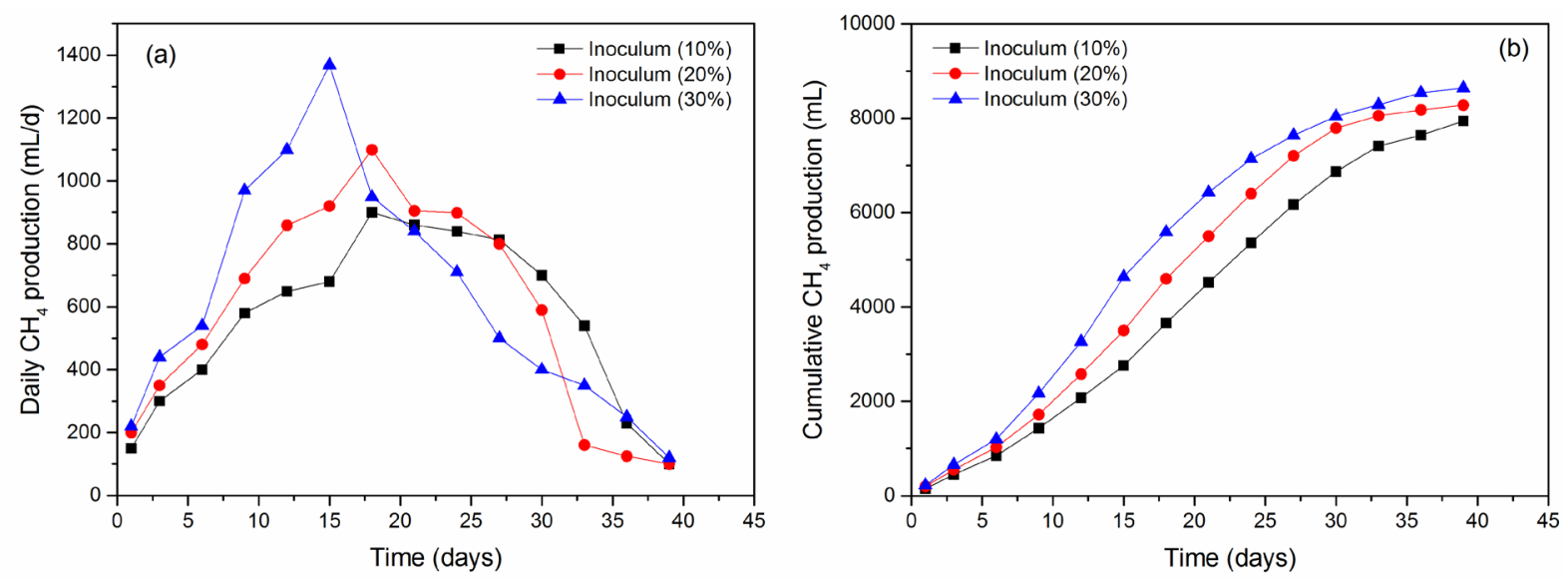

Figure 4. Effect of inoculum percentage on $\mathrm{AD}$ of sawdust 

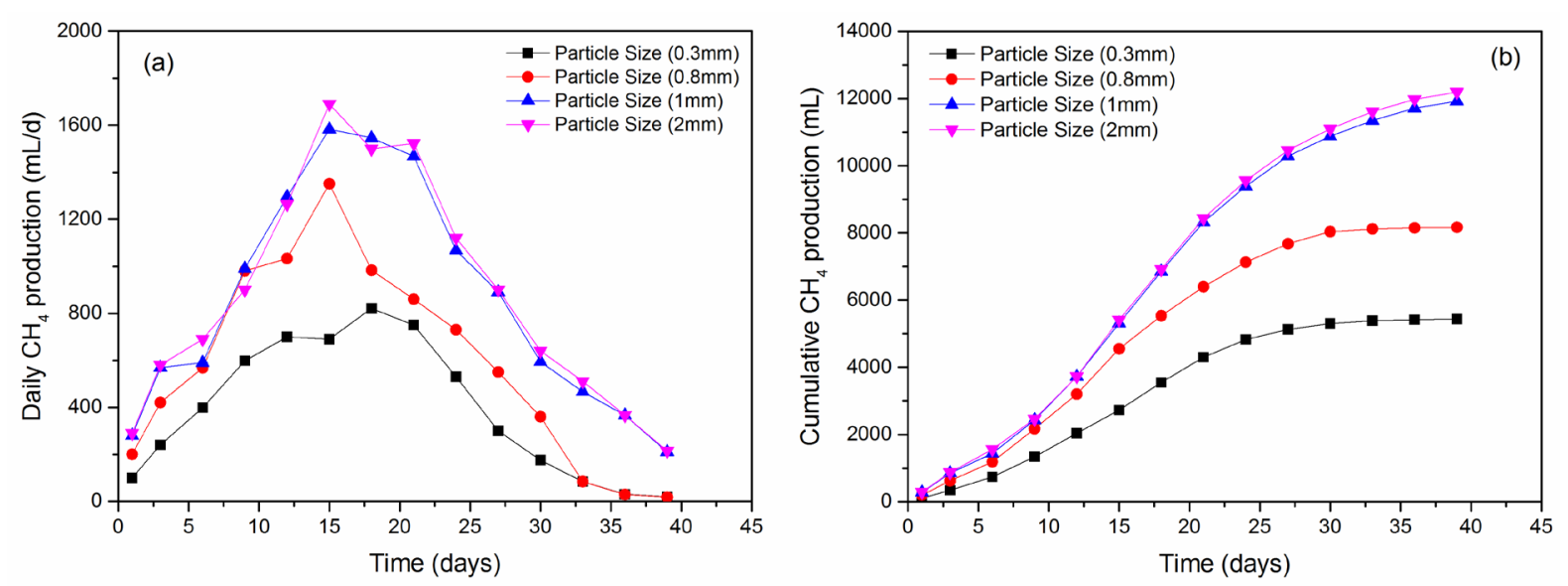

Figure 5. Effect of particle size on $\mathrm{AD}$ of sawdust

cantly higher in the digester with $2.5 \mathrm{~mm}$ (fine) particle size compared to other reactors (Agyeman \& Tao, 2014). On the other hand, De la Rubia et al. evaluated three particles size ranges of (1) $0.355-0.55 \mathrm{~mm}$, (2) $0.710-1.0 \mathrm{~mm}$ and (3) $1.4-2.0 \mathrm{~mm}$. They showed that the highest methane yield was obtained for the largest particle size analysed (3) (De la Rubia et al., 2011).

The last parameter investigated was total solid (TS) content. Three different contents were checked $(5 \%, 10 \%$, and $15 \%)$ and the results were illustrated in Figure 6. As can be seen in Figure 6, the $\mathrm{CH}_{4}$ production increased along with the TS content. This result was consistent with a previous work (Yi et al., 2014). For daily methane produced, highest methane was achieved by TS content with $15 \%$, which was 1.30 and 1.19 -fold higher than other TS contents, $5 \%$ and $10 \%$, respectively (Figure 6a). In addition, the cumulative $\mathrm{CH}_{4}$ production had the same trend with respect to $15 \%$ TS content, where $15 \%$ TS showed a $28 \%$ and $18 \%$ more cumulative $\mathrm{CH}_{4}$ than other
TS contents, respectively (Figure 6b). These results agreed with previous studies, which proposed that the increase of feeding TS contents lower than $20 \%$ has a favourable effect on the $\mathrm{CH}_{4}$ production (Dai et al., 2013; Yi et al., 2014).

\section{CONCLUSIONS}

Anaerobic digestion of pine sawdust after adsorption of TOC from synthetic domestic wastewater can increase the recovery of energy products from sawdust. The sawdust used in this study showed a good performance in the adsorption process. The removal efficiency of TOC was increased with the decrease in adsorbent particle size, $\mathrm{pH}$, and temperature. In contrast, the efficiency increased along with the contact time. The main $\mathrm{AD}$ conclusions obtained from this study are: the big amount of energy recovered and methane produced from $\mathrm{AD}$ of used sawdust demonstrate the importance of this step after adsorption pro-
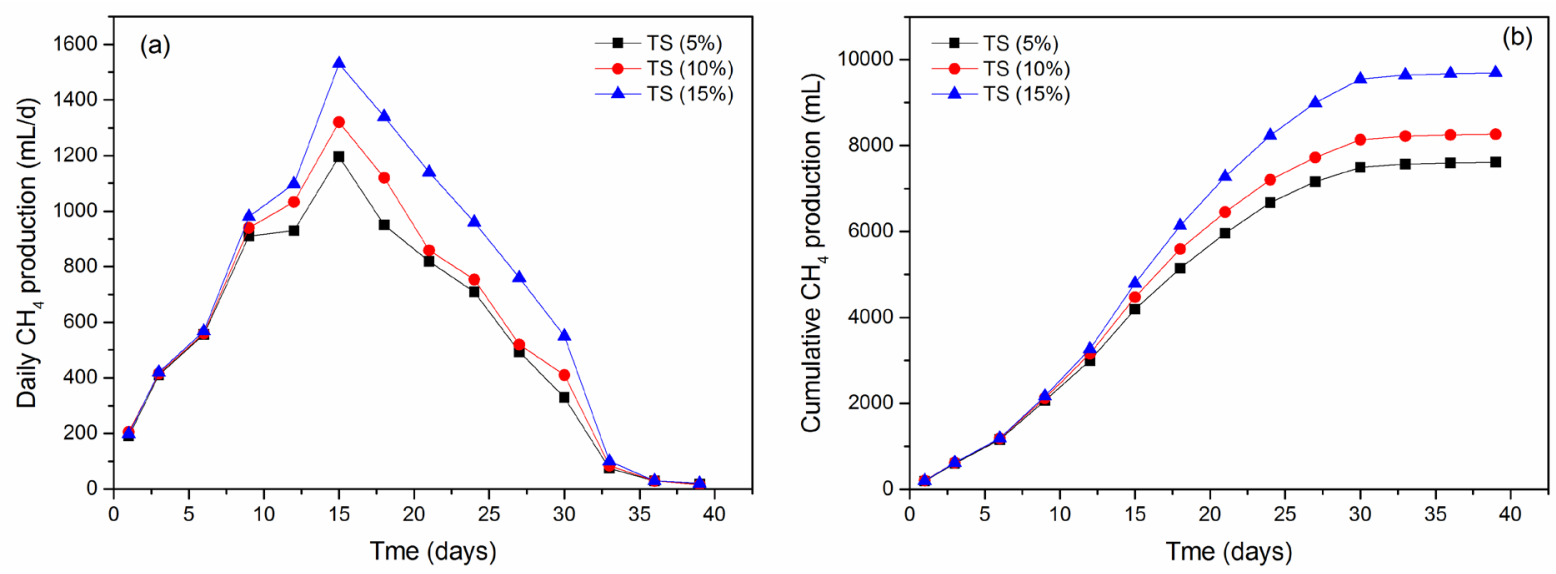

Figure 6. Effect of TS content on AD of sawdust 
cess. In addition, the best operating parameters of $\mathrm{AD}(\mathrm{C} / \mathrm{N}$, inoculation, particle size, and $\mathrm{TS})$ were: $20 \%, 30 \%, 2 \mathrm{~mm}$, and $15 \%$, respectively.

\section{Acknowledgements}

The author would like to thank Al-Mustansiriyah University Baghdad in Iraq for its support in the present work.

\section{REFERENCES}

1. Agyeman, F.O., Tao, W. 2014. Anaerobic co-digestion of food waste and dairy manure: Effects of food waste particle size and organic loading rate. Journal of Environmental Management, 133, 268-274.

2. Ahn, Y., Logan, B.E. 2010. Effectiveness of domestic wastewater treatment using microbial fuel cells at ambient and mesophilic temperatures. Bioresource technology, 101(2), 469-475.

3. Benetti, A.D. 2008. Water reuse: issues, technologies, and applications. Engenharia Sanitaria e Ambiental, 13(3), 247-248.

4. Castoldi, R., Correa, V.G., de Morais, G.R., de Souza, C.G., Bracht, A., Peralta, R.A., Moreira, R.F.P.-M., Peralta, R.M. 2017. Liquid nitrogen pretreatment of eucalyptus sawdust and rice hull for enhanced enzymatic saccharification. Bioresource technology, 224, 648-655.

5. Dai, X., Duan, N., Dong, B., Dai, L. 2013. Highsolids anaerobic co-digestion of sewage sludge and food waste in comparison with mono digestions: Stability and performance. Waste Management, 33(2), 308-316.

6. De la Rubia, M.A., Fernández-Cegrí, V., Raposo, F., Borja, R. 2011. Influence of particle size and chemical composition on the performance and kinetics of anaerobic digestion process of sunflower oil cake in batch mode. Biochemical Engineering Journal, 58-59(0), 162-167.

7. Dechrugsa, S., Kantachote, D., Chaiprapat, S. 2013. Effects of inoculum to substrate ratio, substrate mix ratio and inoculum source on batch codigestion of grass and pig manure. Bioresource Technology, 146, 101-108.

8. El-Naas, M.H., Al-Zuhair, S., Alhaija, M.A. 2010. Reduction of COD in refinery wastewater through adsorption on date-pit activated carbon. Journal of Hazardous Materials, 173(1-3), 750-757.

9. Federation, W.E., Association, A. 2005. Standard methods for the examination of water and wastewater. American Public Health Association (APHA): Washington, DC, USA.

10. Ghaedi, M., Sadeghian, B., Pebdani, A.A., Sah- raei, R., Daneshfar, A., Duran, C. 2012. Kinetics, thermodynamics and equilibrium evaluation of direct yellow 12 removal by adsorption onto silver nanoparticles loaded activated carbon. Chemical Engineering Journal, 187, 133-141.

11. Gupta, V., Agarwal, A., Singh, M. 2015. Belpatra (aegel marmelos) bark powder as an adsorbent for the color removal of textile dye "torque blue". Int J Sci Eng Tech, 4(2), 56-60.

12. Haider, M.R., Zeshan, Yousaf, S., Malik, R.N., Visvanathan, C. 2015. Effect of mixing ratio of food waste and rice husk co-digestion and substrate to inoculum ratio on biogas production. Bioresource Technology, 190(0), 451-457.

13. Huerta-Fontela, M., Galceran, M.T., Ventura, F. 2011. Occurrence and removal of pharmaceuticals and hormones through drinking water treatment. Water research, 45(3), 1432-1442.

14. Katsoyiannis, A., Samara, C. 2005. Persistent organic pollutants (POPs) in the conventional activated sludge treatment process: fate and mass balance. Environmental Research, 97(3), 245-257.

15. Kazemi, S.Y., Biparva, P., Ashtiani, E. 2016. Cerastoderma lamarcki shell as a natural, low cost and new adsorbent to removal of dye pollutant from aqueous solutions: Equilibrium and kinetic studies. Ecological Engineering, 88, 82-89.

16. Khamparia, S., Jaspal, D. 2016. Investigation of adsorption of Rhodamine B onto a natural adsorbent Argemone mexicana. Journal of Environmental Management, 183, Part 3, 786-793.

17. Kimming, M., Sundberg, C., Nordberg, Å., Baky, A., Bernesson, S., Norén, O., Hansson, P.-A. 2011. Biomass from agriculture in small-scale combined heat and power plants-a comparative life cycle assessment. Biomass and bioenergy, 35(4), 1572-1581.

18. Liu, Q., Liu, Q., Ma, W., Liu, W., Cai, X., Yao, J. 2016. Comparisons of two chelating adsorbents prepared by different ways for chromium (VI) adsorption from aqueous solution. Colloids and Surfaces A: Physicochemical and Engineering Aspects, 511, 8-16.

19. Lizasoain, J., Rincón, M., Theuretzbacher, F., Enguídanos, R., Nielsen, P.J., Potthast, A., Zweckmair, T., Gronauer, A., Bauer, A. 2016. Biogas production from reed biomass: Effect of pretreatment using different steam explosion conditions. Biomass and Bioenergy, 95, 84-91.

20. Mor, S., Chhoden, K., Ravindra, K. 2016. Application of agro-waste rice husk ash for the removal of phosphate from the wastewater. Journal of Cleaner Production, 129, 673-680.

21. Rickert, D.A., Hunter, J.V. 1971. General nature of soluble and particulate organics in sewage and secondary effluent. Water Research, 5(7), 421-436. 
22. Shukla, P., Fatimah, I., Wang, S., Ang, H., Tadé, M.O. 2010. Photocatalytic generation of sulphate and hydroxyl radicals using zinc oxide under lowpower UV to oxidise phenolic contaminants in wastewater. Catalysis Today, 157(1), 410-414.

23. Speece, R.E. 2007. Anaerobic biotechnology and odor/corrosion control for municipalities and industries. Nashville (Ten.) : Archae press.

24. Yang, H.I., Lou, K., Rajapaksha, A.U., Ok, Y.S., Anyia, A.O., Chang, S.X. 2017. Adsorption of ammonium in aqueous solutions by pine sawdust and wheat straw biochars. Environmental Science and Pollution Research, 1-10.

25. Yen, H.-W., Brune, D.E. 2007. Anaerobic co-digestion of algal sludge and waste paper to produce methane. Bioresource Technology, 98(1), 130-134.

26. Yi, J., Dong, B., Jin, J., Dai, X. 2014. Effect of increasing total solids contents on anaerobic digestion of food waste under mesophilic conditions: performance and microbial characteristics analysis. PloS one, 9(7), e102548.

27. Yin, C.Y., Aroua, M.K., Daud, W.M.A.W. 2007. Review of modifications of activated carbon for enhancing contaminant uptakes from aqueous solutions. Separation and Purification Technology, 52(3), 403-415.

28. Zhang, Y., Banks, C.J. 2013. Impact of different particle size distributions on anaerobic digestion of the organic fraction of municipal solid waste. Waste Management, 33(2), 297-307. 